\title{
Identifikasi Genangan Banjir yang Terjadi di Kecamatan Cikampek, Kabupaten Karawang
}

\author{
Deandra Auliana Izmah", ${ }^{1, a}$ Eka Wardhani ${ }^{2, b}$, M. Candra Nugraha ${ }^{3, c}$ \\ ${ }^{1}$ Jurusan Teknik Lingkungan Fakultas Teknit Sipil dan Perencanaan Institut Teknologi Bandung \\ 2 Jurusan Teknik Lingkungan Fakultas Teknit Sipil dan Perencanaan Institut Teknologi Bandung \\ adeandraul28@gmail.com
}

\begin{abstract}
Abstrak.
Kecamatan Cikampek merupakan salah satu kecamatan di Kabupaten Karawang yang terletak di bagian Tenggara wilayah Kabupaten Karawang. Kecamatan Cikampek termasuk kawasan yang tumbuh pesat akibat pengembangan kawasan peruntukan industri, serta permukiman perkotaan. Penelitian ini bertujuan untuk menentukan genangan banjir yang harus segera ditanggulangi. Metode penelitian dilakukan dengan cara observasi di lapangan dan wawancara dengan pihak terkait. Berdasarkan hasil penelitian di Kecamatan Cikampek terjadi genangan dengan luas genangan $274 \mathrm{Ha}$, ketinggian genangan 10-40 cm, lama pengaliran 3 jam/hari, dan frekuensi genangan (9 kali/tahun) disebabkan luapan saluran pembuang sekunder yaitu Sungai Cikaranggelam. Terdapat tiga daerah prioritas yang harus segera ditangani system drainasenya yaitu Desa Cikampek Selatan, Dawuan Tengah, dan Dawuan Barat.
\end{abstract} Kata kunci. Banjir, Cikampek, Dawuan, Drainase, Genangan

\begin{abstract}
.
Cikampek District is one of the sub-districts in the Karawang Regency located in the Southeast part of the Karawang Regency area. Cikampek sub-district is one of the areas that is growing rapidly due to the development of industrial allotment areas and urban settlements. This study aims to determine the flood inundation that must be addressed immediately. The research method was carried out by observation in the field and interviews with related parties. Based on the results of research in the District of Cikampek, there was inundation with an area of $274 \mathrm{Ha}$, inundation height of 10-40 cm, drainage time of 3 hours / day, and inundation frequency (9 times / year) due to overflow of secondary drainage channel namely Cikaranggelam River. There are three priority areas that the drainage system must immediately address, namely Desa Cikampek Selatan, Dawuan Tengah and Dawuan Barat.
\end{abstract}

Keywords. Flood, Cikampek, Dawuan, Drainage, Inundation 


\section{PENDAHULUAN}

Kabupaten Karawang merupakan salah satu kabupaten yang berada di bagian Utara Provinsi Jawa Barat yang mengalami perkembangan pesat terutama di sektor industri dan infrastruktur. Sampai saat ini Kabupaten Karawang belum memiliki drainase yang memadai, terutama di sepanjang pinggiran jalan nasional dan provinsi. Ketika hujan jalan tergenang air sehingga konstruksi jalan rawan mengelupas. Salah satu sistem drainase yang buruk yaitu berada di Kecamatan Cikampek (Strategi Sanitasi Kota/SSK Karawang, 2018).

Kecamatan Cikampek termasuk kawasan yang tumbuh pesat akibat pengembangan kawasan peruntukan industri, serta permukiman perkotaan. Hal ini dibuktikan dengan adanya perluasan lahan untuk memenuhi kebutuhan masyarakat yang menimbulkan perubahan tata guna lahan. Dampak dari kegiatan tersebut menyebabkan kurangnya resapan air sehingga volume aliran permukaan (surface run-off) meningkat yang mengakibatkan terjadinya banjir. Penelitian ini bertujuan untuk mengetahui lokasi genangan banjir yang terjadi di Kecamatan Cikampek Kabupaten Karawang Provinsi Jawa Barat. Teridentifikanya daerah genangan akan membantu menentukan prioritas penanganan banjir sehingga tepat sasaran. Metode penelitian menggunakan penelusuran data sekunder dan wawancara dengan pemangku kepentingan di sektor drainase dan masyarakat di Kecamatan Cikampek.

\section{METODOLOGI PENELITIAN}

Tahapan penelitian diawali dengan identifikasi masalah, studi pustaka, pengumpulan data, dan analisis data. Studi pustaka dilakukan pada tahapan awal sebagai pendukung dalam penelitian. Studi pustaka berasal dari jurnal, buku dan referensi lainnya yang terkait. Selain itu, tahap ini dapat dijadikan dasar atau landasan teori serta acuan dalam membandingkan kondisi eksisting di lapangan dengan studi literatur.

Pengumpulan data terdiri dari data primer dan sekunder yang diperlukan dalam identifikasi daerah genangan di Kecamatan Cikampek, Kabupaten Karawang. Data primer merupakan data yang didapatkan dari hasil pengamatan secara langsung di lokasi studi. Data primer yang diperoleh antara lain: kondisi wilayah penelitian secara umum, kondisi badan air penerima, dimensi saluran dan identifikasi permasalahan drainase eksisting. Data sekunder diperoleh dari instansi terkait yang berhubungan langsung dengan penelitian Data sekunder yang dikumpulkan disajikan pada Tabel 1. Analisis data dilakukan secara deskriptif setelah proses pengumpulan data selesai.

Tabel 1. Data Sekunder Perencanaan

\begin{tabular}{clc}
\hline No. & \multicolumn{1}{c}{ Data yang diperlukan } & Sumber Data \\
\hline 1 & Peta tata guna lahan dan topografi Kecamatan Cikampek & BAPPEDA Kabupaten Karawang \\
2 & RTRW Kecamatan Cikampek & BAPPEDA Kabupaten Karawang \\
3 & SSK Karawang & BAPPEDA Kabupaten Karawang \\
\hline
\end{tabular}


Sumber: Hasil Pengolahan Data, 2019

\section{HASIL, PEMBAHASAN DAN ANALISA}

Cikampek adalah sebuah kecamatan di Kabupaten Karawang, Provinsi Jawa Barat, Indonesia. Kecamatan Cikampek terletak di sebelah Tenggara Kabupaten Karawang dan memiliki jarak $25 \mathrm{Km}$ dari pusat kota. Luas wilayah Kecamatan Cikampek tercatat 46,79 Km2. Secara geografis, terletak di bagian Utara Kabupaten Karawang dengan batas koordinat yaitu 6³0'00'LU-

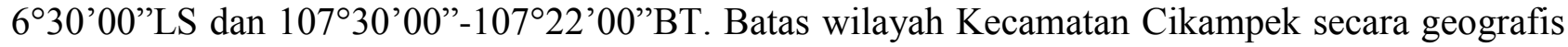
adalah sebelah Utara berbatasan dengan Kecamatan Tirtamulya, sebelah Timur dengan Kecamatan Kotabaru, sebelah Selatan dengan Kecamatan Klari dan Kabupaten Purwakarta, serta sebelah Barat dengan Kecamatan Purwasari. Peta Administarsi Kecamatan Cikampek dapat dilihat pada Gambar 1 .

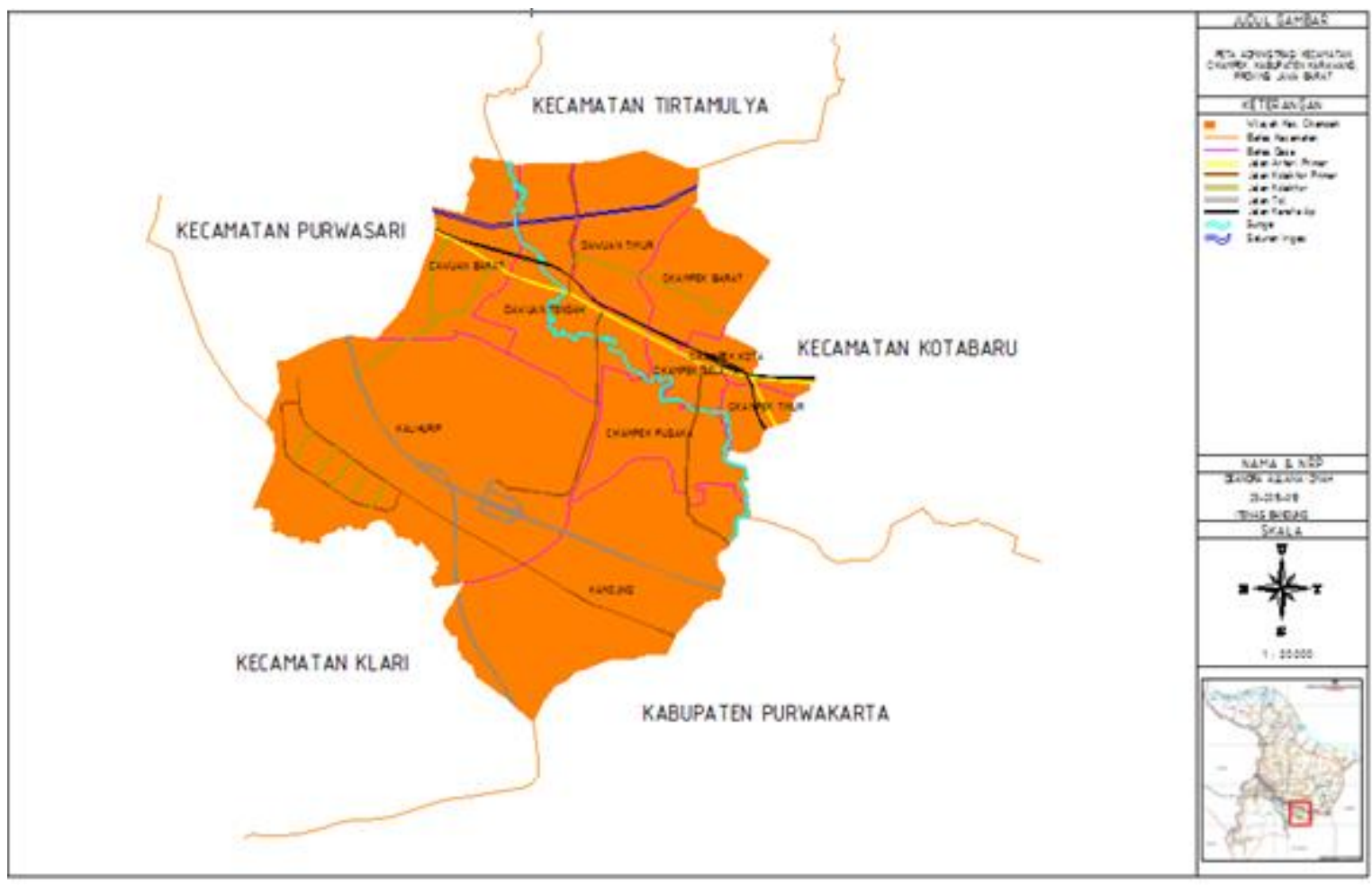

Gambar 1. Peta Administarsi Kecamatan Cikampek

Kecamatan Cikampek memiliki tinggi wilayah $\pm 25 \mathrm{~m}$ di atas permukaan laut. Kecamatan ini memiliki 10 kecamatan seperti disajikan pada Tabel 2. Berdasarkan Tabel 2 dapat disimpulkan bahwa luas wilayah terbesar yaitu Desa Kalihurip sebesar 19,91 Km2 dengan persentase terhadap luas kecamatan sebesar 42,55\% dan luas wilayah terkecil yaitu Desa Cikampek Kota sebesar 0,97 $\mathrm{Km} 2$ dengan persentase terhadap luas kecamatan sebesar 2,07\%. 
Tabel 2. Luas Wilayah dan Persentase terhadap Luas Kecamatan, Jumlah serta Kepadatan Penduduk di di Kecamatan Cikampek

\begin{tabular}{clcccc}
\hline No & \multicolumn{1}{c}{ Desa } & $\begin{array}{c}\text { Luas } \\
\text { Wilayah } \\
\left(\mathrm{Km}^{2}\right)\end{array}$ & $\begin{array}{c}\text { Persentase } \\
\text { terhadap Luas } \\
\text { Kecamatan (\%) }\end{array}$ & $\begin{array}{c}\text { Jumlah } \\
\text { Penduduk } \\
(\text { Jiwa })\end{array}$ & $\begin{array}{c}\text { Tingkat } \\
\text { Kepadatan } \\
\text { Penduduk } \\
\text { (Jiwa/km²) }\end{array}$ \\
\hline 1 & Kalihurip & 19,91 & 42,55 & 4.046 & 203 \\
2 & Kamojing & 12,31 & 26,31 & 3.710 & 301 \\
3 & Cikampek Timur & 1,18 & 2,52 & 9.863 & 8.806 \\
4 & Cikampek Pusaka & 1,187 & 2,54 & 4.185 & 2.238 \\
5 & Cikampek Selatan & 1,22 & 2,61 & 9.485 & 7.775 \\
6 & Cikampek Kota & 0,97 & 2,07 & 7.212 & 7.435 \\
7 & Cikampek Barat & 1,94 & 4,15 & 17.532 & 9.037 \\
8 & Dawuan Timur & 2,8 & 5,98 & 9.398 & 3.356 \\
9 & Dawuan Tengah & 2,27 & 4,85 & 17.957 & 7.911 \\
10 & Dawuan Barat & 2,32 & 4,96 & 14.005 & 4.390 \\
& Kecamatan & 46,79 & 100 & 97.393 & 2.046 \\
\hline
\end{tabular}

Sumber: Kecamatan Cikampek Dalam Angka 2018

Pertumbuhan kota dan perkembangan sektor lainnya menimbulkan dampak yang cukup besar pada siklus Hidrologi, sehingga berpengaruh besar terhadap sistem drainase. Pertambahan jumlah penduduk juga menjadi masalah sendiri bagi daya tampung drainase. Selain itu bertambahnya jumlah penduduk seiring dengan bertambahnya infrastruktur bangunan-bangunan yang mengakibatkan semakin sedikit daerah resapan air.

Kecamatan Cikampek memiliki luas wilayah 47,69 Km2 yang dihuni oleh 97.393 jiwa. Tingkat kepadatan penduduk di wilayah Kecamatan Cikampek adalah 2.046 jiwa/Km2. Jumlah dan kepadatan penduduk di Kecamatan Cikampek pada tahun 2017 dapat dilihat pada Tabel 2. Berdasarkan Peraturan Daerah Kabupaten Karawang Nomor 2 Tahun 2013 tentang Rencana Tata Ruang Wilayah (RTRW) Kabupaten Karawang tahun 2011-2031, Kecamatan Cikampek merupakan salah satu kawasan rawan bencana banjir. Genangan banjir menggenangi jalan dan perumahan. Berdasarkan SSK Kabupaten Karawang tahun 2018, di Kecamatan Cikampek terjadi genangan dengan luas $274 \mathrm{Ha}$, dengan ketinggian 10-40 cm, lama pengaliran 3 jam/hari, dan frekuensi genangan (9 kali/tahun). Penyebab genangan yaitu luapan saluran pembuang sekunder yaitu Sungai Cikaranggelam.

Menurut Kecamatan Cikampek Dalam Angka 2018, Kecamatan Cikampek memiliki luas wilayah 47,69 Km2 atau 4.769 Ha dan jumlah penduduk 97.393 jiwa dengan kepadatan penduduk 2.046 jiwa/Km2. Kecamatan Cikampek merupakan salah satu kecamatan di Kabupaten Karawang yang terletak di bagian Tenggara wilayah Kabupaten Karawang. Kecamatan Cikampek terdiri dari 10 desa dengan ibukota kecamatan berada di Desa Cikampek Selatan. Kecamatan Cikampek terdapat titik banjir/genangan di Desa Cikampek Selatan, Dawuan Tengah, dan Dawuan Barat. Wilayah Desa Cikampek Selatan sering mengalami banjir di Gang Kopti RW 9, karena meluapnya air dari Situ Kamojing diteruskan melalui Sungai Cikaranggelam ke wilayah dataran rendah yaitu RW 9. Perubahan alih fungsi lahan menjadi pemukiman dekat Sungai Cikaranggelam menjadikan pendangkalan dan saluran sudah tidak mampu menampung air dengan kapasitas yang tinggi. Desa Dawuan Tengah dan Barat terjadi banjir akibat meluapnya saluran irigasi Tarum Timur, serta 
kiriman Sungai Cikaranggelam yang berdampak pada wilayah dataran rendah yaitu Bumi Mutiara Indah (BMI) 1 di Desa Dawuan Tengah dan BMI 2 di Desa Dawuan Barat.

Rencana Pembangunan Jangka Menengah Daerah (RPJMD) Kabupaten Karawang tahun 2016-2021, salah satu permasalahan yang telah diidentifikasi yaitu belum optimalnya penyediaan infrastruktur wilayah yang memenuhi standar optimum minimal dan belum terintegrasinya penataan sarana dan prasarana diantaranya saluran drainase. Berdasarkan hal tersebut, dibutuhkan perencanaan sistem drainase di Kecamatan Cikampek, Kabupaten Karawang untuk mengetahui cara penanganan yang tepat pada daerah tersebut sehingga masalah genangan air hujan dapat disalurkan dan banjir dapat dihindari. Aliran air permukaan yang berdampak terjadinya banjir dan erosi dapat dicegah sehingga terhindar dari resiko terhadap kesehatan, kerugian ekonomi, masalah terhadap infrastruktur perkotaan, serta aktivitas masyarakat tidak akan terganggu.

Sistem drainase di kawasan perkotaan Kabupaten Karawang, pada umumnya terdiri dari saluran buatan (irigasi) dan anak sungai DAS Citarum sebagai saluran drainase primer dan sekunder, yang kemudian dialirkan ke saluran pembuangan akhir yaitu sungai yang lebih besar (Sungai Citarum).

Berdasarkan pendataan bencana banjir Kecamatan Cikampek tahun 2018 dan Dinas Pekerjaan Umum dan Penataan Ruang Kabupaten Karawang, tercatat titik banjir pada Desa Cikampek Selatan, Dawuan Tengah, dan Dawuan Barat dapat dilihat pada Gambar 2. Pada Desa Cikampek Selatan berada di RW 09, sedangkan pada Desa Dawuan Tengah dan Barat berada di Perumahan BMI (Bumi Mutiara Indah) 1 dan 2.

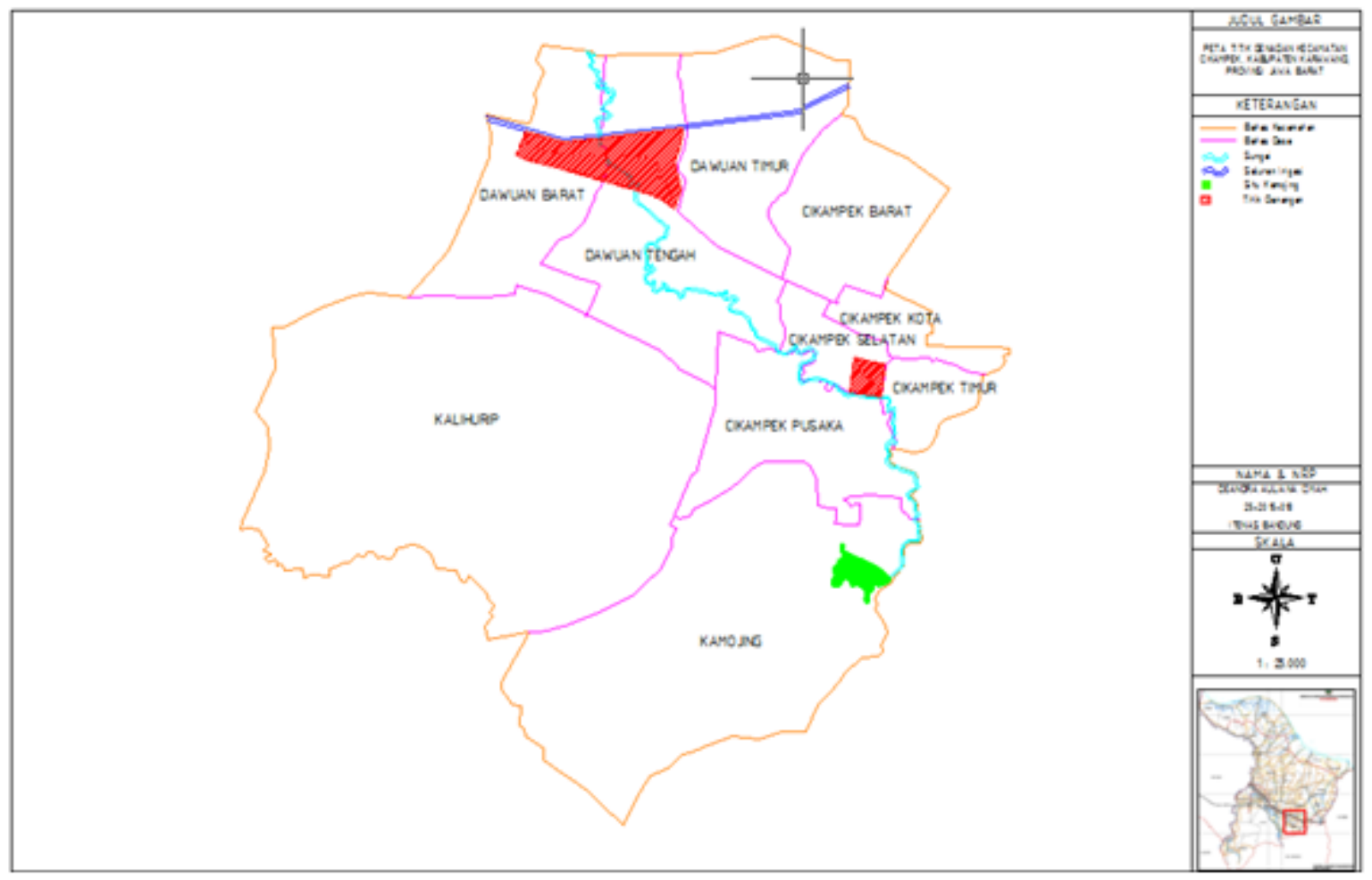

Gambar 2. Peta Titik Genangan Kecamatan Cikampek.

Permasalahan banjir pada Desa Cikampek Selatan yaitu Gang Kopti di RW 9. Hal ini sebabkan karena sudah tidak tertampungnya air hujan yang masuk ke Situ Kamojing yang berada di Desa Kamojing, sehingga meluap dan dibukanya pintu air Situ Kamojing (Gambar 3) sehingga air terbagi ke Sungai Cikaranggelam yang melewati dataran rendah yaitu Gang Kopti di RW 9. Serta, semakin meluasnya pemukiman akibat perluasan tata guna lahan di atas Sungai Cikaranggelam 
menyebabkan terjadinya pengikisan dan air pun meluap ke pemukiman warga. Tinggi genangan pada lokasi tersebut mencapai 0,25 m dengan durasi banjir selama 3 jam. Kondisi saluran RW 9 dapat dilihat pada Gambar 3.

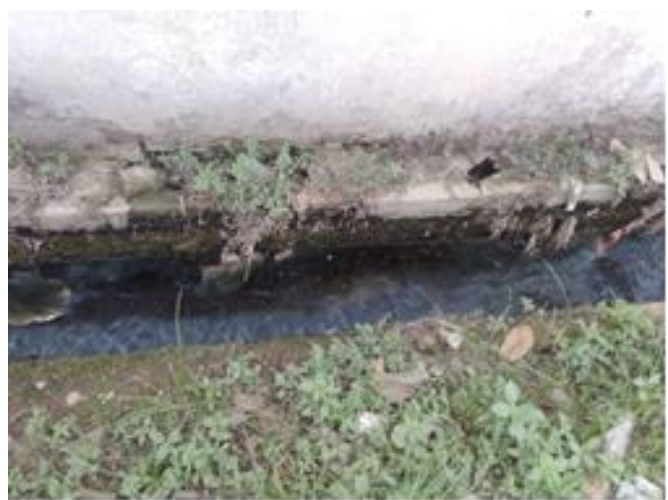

(a)

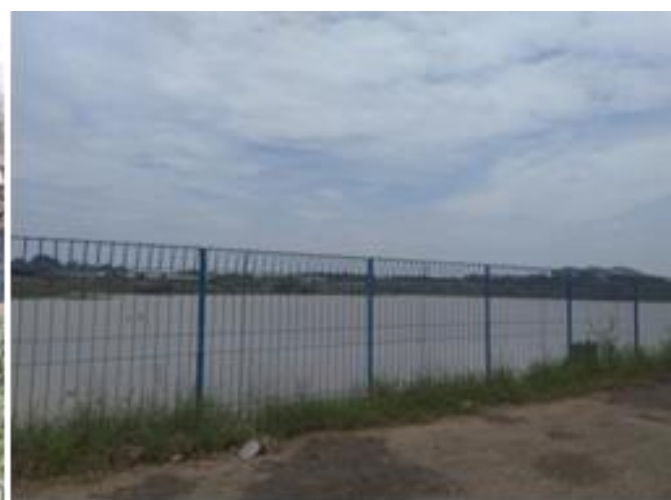

(b)

Gambar 3. (a) Kondisi Saluran Drainase RW 09 dan (b) Situ Kamojing

Permasalahan banjir pada Desa Dawuan Tengah berada di Perumahan BMI (Bumi Mutiara Indah) 1 dan Desa Dawuan Barat di Perumahan BMI 2 yang merupakan dataran rendah dan dekat dengan saluran Irigasi Tarum Timur. Penyebab wilayah tersebut terkena banjir karena meluapnya saluran Irigasi Tarum Timur yang mendapat kiriman air dari Sungai Cikaranggelam apabila pintu air Situ Kamojing terbuka. Tinggi genangan pada BMI 1 dapat mencapai 0,5-0,75 m dan BMI 2 dapat mencapai 1-1,5 m dengan durasi banjir selama 3-4 jam. Kondisi saluran drainase eksisting di Perumahan BMI 1 dan 2 dapat di lihat pada Gambar 4.

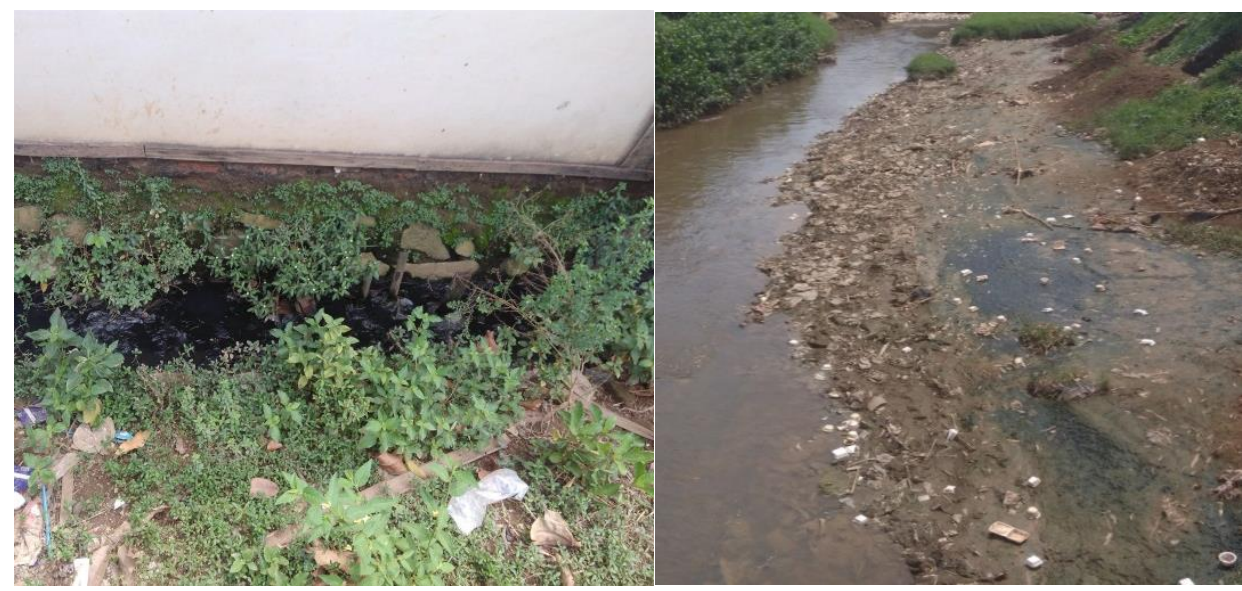

(a) (b)

Gambar 4. (a) Kondisi Saluran Drainase Perumahan BMI 1 dan 2 dan (b) Sungai Cikaranggelam

\section{KESIMPULAN}

Identifikasi genangan banjir di Kecamatan Ciakmpek dapat dilakukan dengan cara observasi di lapangan dan wawancara dengan pihak terkait. Terdapat tiga daerah prioritas yang harus segera ditangani sistem drainasenya yaitu Desa Cikampek Selatan, Dawuan Tengah, dan Dawuan Barat. Penyebab genangan yang terjadi di Desa Cikampek Selatan disebabkan meluapnya Situ Kamojing, perubahan alih fungsi lahan menjadi pemukiman dan saluran sudah tidak mampu menampung air dengan kapasitas yang tinggi. Desa Dawuan Tengah dan Barat disebabkan meluapnya saluran irigasi Tarum Timur. 


\section{DAFTAR PUSTAKA}

1. Kecamatan Cikampek Dalam Angka, 2018, Kecamatan Cikampek Dalam Angka, Karawang

2. RPJMD Kabupaten Karawang, 2016, Rencana Pembangunan Jangka Menengah Daerah Kabupaten Karawang 2016-2021, Pemerintah Kabupaten Karawang, Karawang

3. SSK Karawang, 2018, Strategi Sanitasi Kabupaten Karawang, Pemerintah Kabupaten Karawang, Karawang 